\title{
Neisseria gonorrhoeae: stability of typing markers after natural transmission
}

\author{
C G COPLEY, C P CHISWELL, AND S I EGGLESTONE \\ From the Public Health Laboratory, Myrtle Road, Kingsdown, Bristol
}

SUMMARY The gonococcal isolates from 15 contact pairs and three large contact groups were examined using various methods to assess the stability of different typing markers. With the exception of one contact group which showed variable proline requirements, the auxotypes were stable during natural transmission. Serogrouping using the coagglutination method to detect $\mathrm{W}$ and $M$ antigens was undertaken. The lipopolysaccharide $M$ antigens were readily lost and gained during transmission whereas the protein $\mathrm{W}$ antigens represented stable markers and are thus useful for epidemiological studies.

\section{Introduction}

To obtain a better understanding of the epidemiology of gonococcal infections reliable methods of distinguishing between strains of Neisseria gonorrhoeae are necessary. The discovery by Catlin ${ }^{1}$ that $N$ gonorrhoeae could be divided into subgroups based on their nutritional requirements provided the first practical method of typing gonococci, which has become invaluable in epidemiological investigations. ${ }^{2-4}$ Until recently, attempts at defining an accepted pattern of serotypes among gonococci have failed. With improved knowledge of the composition of the gonococcal outer surface, however, reproducible serotyping methods have been developed. The outer surface of the gonococcus is a complex structure containing lipopolysaccharide and proteins. Several workers have examined these constituents as possible candidates for the basis of serotyping schemes by various methods. ${ }^{5-10}$ Danielsson and Sandstrom ${ }^{11}$ and Sandstrom and Danielsson ${ }^{12}$ recently classified gonococci serologically by the coagglutination (COA) method. Applying the COA tests to the 16 major outer membrane protein (MOMP) reference strains of Johnston et $a l^{6}$ these workers proposed a multifactor model to explain the antigenic composition of the gonococcal outer membrane based on three classes of antigens-tentatively named $W, J$, and $M$. The antigens of class $W$ were divided into three groups-I, II, and III-and are protein in nature. Class $\mathbf{J}$ antigens are partly sensitive to pronase and are shared only by closely

Address for reprints: Dr S I Egglestone, Public Health Laboratory, Myrtle Road, Kingsdown, Bristol BS2 8EL

Accepted for publication 4 January 1983 related species. The antigens of class $M$ are polysaccharides and were divided into seven groups, a-g.

In this study we investigated the stability of various markers by typing the isolates from 15 pairs of contacts and three larger groups of contacts using auxotyping and serogrouping by $\mathrm{W}$ antigen and $\mathrm{M}$ antigen. Penicillin sensitivity was used as an additional biological marker.

\section{Materials and methods}

\section{STRAINS OF NEISSERIA GONORRHOEAE}

Test strains were selected from 120 consecutive urogenital isolates from the Avon area on the basis of retrospective contact tracing. The strains had been stored at $-70^{\circ} \mathrm{C}$ in horse serum and their identity confirmed by Gram and oxidase reaction and carbohydrate fermentation. Major outer membrane protein strains ${ }^{6}$ were obtained from Dr D Danielsson. All strains were cultured on either chocolate agar or New York City medium at $36^{\circ} \mathrm{C}$ in a humid atmosphere containing $5 \% \mathrm{CO}_{2}$.

\section{AUXOTYPING}

The chemically defined media and technical procedures have been described. ${ }^{13}$ The set of typing media were prepared by omitting the appropriate nutritional requirement from the complete media. Nutritional requirements for proline (Pro), arginine (Arg), hypoxanthine (Hyp), uracil (Ura), and arginine requirement not satisfied by ornithine $\left(\mathrm{Arg}^{\circ}\right)$ were examined.

\section{SEROGROUPING}

This was performed by the coagglutination method of Danielsson and Sandström. ${ }^{11}$ Hyperimmune 
rabbit sera raised against Johnston's MOMP strains D4, E5, V15, N10, S12, U14, and F6 were selectively absorbed with other MOMP strains as indicated in table I. These absorption procedures produced seven W factors and six of the seven $\mathbf{M}$ factors described by Danielsson and Sandstrom. ${ }^{11}$ These reagents gave reactions with the standard MOMP strains as described by Danielsson and Sandström. ${ }^{11}$

Protein A bearing staphylococci, prepared according to the method of Kessler, ${ }^{14}$ were coated with the absorbed antisera. Test strains of $N$ gonorrhoeae were prepared by boiling a $1 \%(\mathrm{w} / \mathrm{v})$ suspension for one hour. One drop of the coated staphylococci was mixed with an equal volume of the

TABLE I Gonococcal major outer membrane protein reference strains used for immunisation and absorptions for preparation of coagglutination reagents

\begin{tabular}{lll}
\hline Factor & Antisera & Absorbing strains \\
\hline WI & Anti D4 & A1 and C3 \\
WI & Anti E5 & N10 and C3 \\
WI & Anti V15 & N10 and C3 \\
WII & Anti N10 & D4 and E5 \\
WII & Anti S12 & A1 \\
WII & Anti U14 & A1 and B2 \\
WIII & Anti F6 & B2 and U14 \\
M/a & Anti F6 & A1 \\
M/b & Anti D4 & B2 and A1 \\
M/c & Anti V15 & D4 and E5 \\
M/d & Anti U14 & S12 and C3 \\
M/e & Anti S12 & N10 and H8 \\
M/f & Anti E5 & R11 and D4 \\
\hline
\end{tabular}

boiled gonococci on a microscope slide and rocked gently for two minutes. Agglutinations were graded from +++ to - (no agglutination). A preparation consisting of staphylococci coated with normal rabbit serum was used as control.

PENICILLIN SENSITIVITY TESTING

This was performed by the method of Shannon et al. ${ }^{15}$

\section{Results}

The results of the auxotyping, serotyping, and $\stackrel{\omega}{\sigma}$ penicillin susceptibility tests are given in tables II and $\stackrel{?}{?}$ III. Serogrouping using the $W$ class factors if correlated well with the auxotyping results for the strains in this study. Members of the Arg Hyp Ura is group consistently serotyped with WI reagents, while other auxogroups (prototrophic (NR), $\operatorname{Pro} \mathrm{Arg}^{\circ}$ 으 Ura; Pro Arg; Pro; Arg) all grouped with WII reagents. No strains were found that reacted with WIII reagents. Serogrouping results using the lipopolysaccharide $M$ class factors, however, could not of be correlated with any auxogroup or W group.

Natural transmission of the disease did not produce any change in the $\mathrm{W}$ group or penicillin susceptibility. The $M$ antigen content of the organism within contact groups was, however, very variable, the antigen appearing to be gained or lost with ease during transmission. The auxotypes remained identical within all contact groups, except group 18,

TABLE III Auxotype, $W$ and $M$ serogroups, and penicillin minimum inhibitory concentrations (MIC) for gonococci isolated from three contact groups

\begin{tabular}{|c|c|c|c|c|c|c|}
\hline \multirow[b]{2}{*}{$\begin{array}{l}\text { Contact } \\
\text { group }\end{array}$} & \multicolumn{3}{|l|}{ Source } & \multicolumn{3}{|l|}{ Contact } \\
\hline & Auxotype & $\begin{array}{l}M I C \\
(\mu g / m l)\end{array}$ & Antigen & Auxotype & $\begin{array}{l}M I C \\
(\mu \mathrm{g} / \mathrm{ml})\end{array}$ & Antigen \\
\hline \multirow[t]{2}{*}{16} & NR & $0 \cdot 1$ & WII, M( & NR & $0 \cdot 1$ & WII; M(NT) \\
\hline & & & & & 0.1 & WII; M(NT) \\
\hline \multirow[t]{3}{*}{17} & NR & 0.8 & WII, M/ & NR & $1 \cdot 0$ & WII; M/abcf \\
\hline & & & & & 0.8 & WII; M/abd \\
\hline & & & & NR & $1 \cdot 0$ & WII; M/abc \\
\hline \multirow[t]{3}{*}{18} & NR & 0.07 & WII, M/ & Pro Arg & 0.08 & WII; M/abce \\
\hline & & & & Arg & 0.07 & WII; M(NT) \\
\hline & & & & Pro Arg & 0.08 & WII; M(NT) \\
\hline
\end{tabular}

$\mathrm{NT}=$ not tested; $\mathrm{NR}=$ protrophic 


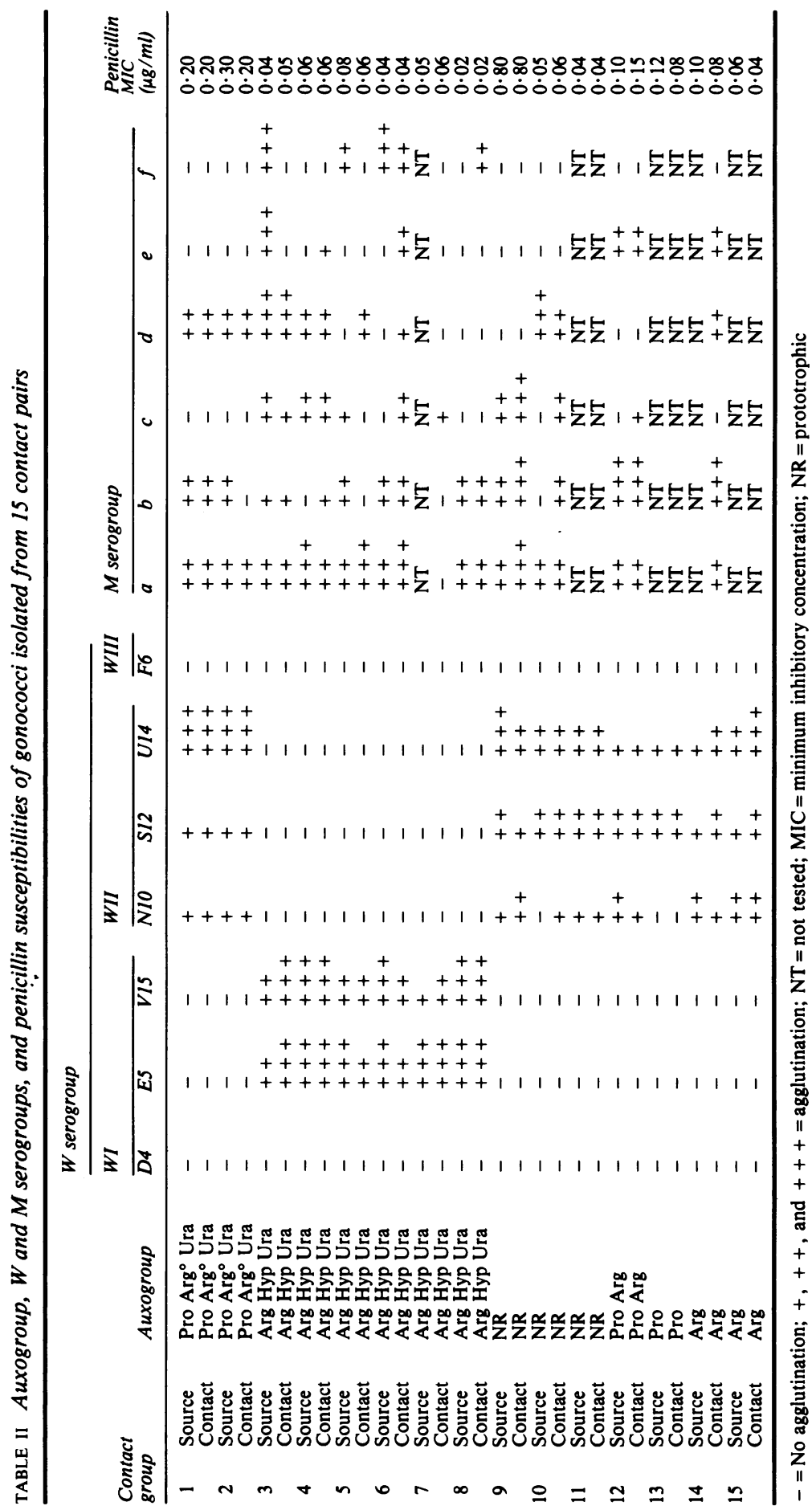


though the $\mathrm{W}$ antigens and penicillin susceptibility remained the same (table III).

Repeated daily subculture of representative strains on chocolate agar or New York City medium produced no change in auxogroup or $W$ or $M$ serogroup.

\section{Discussion}

When considering the usefulness of typing methods for epidemiological purposes it is important to establish the stability of the chosen marker not only during laboratory subculture but also during natural transmission. The latter may never be established unequivocally. Even in sexually transmitted diseases, in which transmission usually occurs on a one to one basis, establishment of correct contacts can be influenced by the patient's reticence. It is essential to use more than one typing scheme when trying to differentiate between a given marker changing during transmission of infection and the source of infection being one other than that claimed. To this end we have used multiple typing systems.

From the results of this study the lipopolysaccharide $M$ antigens do not seem to provide suitable epidemiological markers since they are readily lost and gained during transmission. Other workers ${ }^{12}$ have also shown that these antigens vary on consecutive isolates from one patient, whereas other serological markers remained constant. It is tempting to speculate that the changing pattern of these antigens may represent a survival mechanism against the host defence systems.

Canadian workers ${ }^{16}$ have shown that the carbohydrate content of the lipopolysaccharides extracted from Kellogg type 1 (T1) colonies is different from that of Kellogg type 4 (T4) colonies. To correlate this difference with change in $M$ antigen one of us (CPC) examined the M antigen of $\mathrm{T} 1$ and T4 colonies but was unable to detect any antigenic shift during the change from T1 to T4 colony types.

W class antigens were stable within all the contact groups examined and thus appear to be useful markers for a serogrouping scheme. The disadvantage is that only three $\mathrm{W}$ groups have been defined, but it may be possible further to subdivide them since they have been shown to be equivalent to the principal outer membrane protein (POMP) groups of Buchanan and Hildebrandt. ${ }^{17}$

In this study we have generally found auxotypes to be stable during natural transmission as indeed have other workers. ${ }^{18}$ In contact group 18 , however, the organism appeared to alter its metabolic requirement changing from prototrophic to proline-arginine requiring to arginine requiring and back to prolinearginine requiring. During this transmission chain the $\mathrm{W}$ group of the organism remained the same as did the penicillin susceptibility. Other workers ${ }^{19}$ have found that a proline requirement may not always be a stable characteristic. In a recent study we showed that a proline requirement may be lost under conditions of slow growth in vitro. ${ }^{13}$ These observations question the validity of using proline as a marker in the auxotyping system or at least advise caution when using this marker. Furthermore, in the same study we highlighted the problems of determining arginine requirements on certain media formulations with low concentrations of glutamate. Clearly, the laboratory test conditions may affect the auxotyping results and should be carefully controlled.

In contact group 18 , it is possible that the source case had a mixed infection, which would account for the variation. We intend further to examine contact chains to answer this and other questions raised in the study.

We thank Dr A E Jephcott, director of the Bristol Public Health Laboratory, for granting permission and facilities to carry out this work, and Dr C Lacey, Special Clinic, Bristol, for providing the contact tracing information.

\section{References}

1. Catlin BW. Nutritional profiles of Neisseria gonorrhoeae, Neisseria meningitidis and Neisseria lactamica in chemically defined media and the use of growth requirements for gonococcal typing. J Infect Dis 1973;128:178-94.

2. Knapp JS, Thornsberry C, Schoolnik GA, Wiesner PJ, Holmes KK, and the Co-operative Study Group. Phenotypic and epidemiological correlates of auxotype in Neisseric gonorrhoeae. J Infect Dis 1978;138: 160-5.

3. Knapp JS, Holmes KK. Disseminated gonococcal infection caused by Neisseria gonorrhoeae with unique nutritiona requirements. J Infect Dis $1975 ; 132: 204-8$.

4. Stewart IO, Hendry AT. Association between the auxogroup of Neisseria gonorrhoeae and the minimal inhibitory concentration of penicillin. Sex Transm Dis 1979;6:247-52.

5. Maeland JA, Kristoffersen T, Hofstad T. Immunochemical investigations on Neisseria gonorrhoeae endotoxin 2 . Serological multispecificity and other properties of phenolwater preparations. Acta Pathol Microbiol Scand (B) 1971; 79:233-8.

6. Johnston KH, Holmes KK, Gotschlich EC. The serological classification of Neisseria gonorrhoeae. Isolation of the outer membrane complex responsible for serotype specificity. $J$ Exp Med 1976; 143:741-57.

7. Buchanan TM, Hildebrandt JE. Antigen-specific serotyping of Neisseria gonorrhoeae; characterisation based upon principal outer membrane protein. Infect Immun 1981;32:985-94.

8. Apicella MA. Serogrouping of Neisseria gonorrhoeae: identification of four immunologically distinct acidic polysaccharides. $J$ Infect Dis $1976 ; 134: 377-83$.

9. Wang SP, Holmes KK, Knapp JS, Ott S, Kyzer DD. Immunological classification of Neisseria gonorrhoeae with micro-immunofluorescence. J Immunol 1977; 119: 795-803.

10. Geizer I. Studies on serogrouping of Neisseria gonorrhoeae. Zentralbl Bakteriol (Orig A) 1975;232:213-20.

11. Danielsson D, Sandström E. The use of antigenic markers for classification of Neisseria gonorrhoeae in clinical epidemiological investigations. In: Danielsson D, Normark S, eds. Genetics and immunobiology of pathogenic Neisseria. Hemavan, Sweden: European Molecular Biology Organization, 1980: 73-9. 
12. Sandstrom E, Danielsson D. Serology of Neisseria gonorrhoeae. Classification by co-agglutination. Acta Pathol Microbiol Scand (B) 1980;88:27-38.

13. Copley CG, Egglestone SI. Auxotyping of Neisseria gonorrhoeae in the United Kingdom. J Med Microbiol (in press).

14. Kessler SW. Rapid isolation of antigens from cells with a staphylococcal protein A-antibody adsorbent: parameters of the interaction of antibody-antigen complexes with protein $\mathbf{A}$. J Immunol 1975; 115: 1617-24.

15. Shannon R, Hedges AJ, Edwards RJ. Distribution of levels of penicillin resistance amongst freshly isolated strains of Neisseria gonorrhoeae. Application of a novel sensitivity assay. Br J Vener Dis 1975;51:246-50.

16. Perry MB, Daoust V, Diena BB, Ashton FE, Wallace R. The lipopolysaccharides of Neisseria gonorrhoeae colony types 1 and 4. Can J Biochem 1975;53:623-9.
17. Sandström E, Knapp JS, Buchanan TB. Serology of Neisseria gonorrhoeae: W-antigen serogrouping by coagglutination and protein 1 serotyping by enzyme-linked immunosorbent assay both detect protein 1 antigens. Infect Immun 1982;35:229-39.

18. Carifo K, Catlin BW. Neisseria gonorrhoeae auxotyping: differentiation of clinical isolates based on growth responses on chemically defined media. Appl Microbiol 1973;26:223-30.

19. Sandström E, Moberg I. Mixed infection as a model for gonococcal adaptation in vivo. In: Danielsson $D$, Normark $S$, eds. Genetics and immunobiology of pathogenic Neisseria. Hemavan, Sweden: European Molecular Biology Organization, 1980:283-87. 